\title{
A Cross Sectional Assessment of Health Literacy among Cardiovascular Patients in Karachi, Pakistan
}

Fahad Saleem $^{1 *}$, Furqan Khurshid Hashmi², Naveel Atif ${ }^{2}$, Nadeem Irfan Bukhari², Muhammad Ahsan ${ }^{2}$, Hamid Saeed ${ }^{2}$, Zikria Saleem ${ }^{2}$ and Mohamed Azmi Hassali ${ }^{1}$

${ }^{1}$ School of Pharmaceutical Sciences, Universiti Sains Malaysia, Malaysia

${ }^{2}$ University College of Pharmacy, University of the Punjab, Lahore, Pakistan

\begin{abstract}
Background: An adequate level of health literacy is related to positive treatment outcomes. The current study is aimed to examine factors associated with health literacy among cardiovascular patients in Karachi city, Pakistan.

Method: The study was designed as a cross sectional, descriptive survey. A pre-validated questionnaire was used for data collection. One hundred and sixty three patients attending the Cardiology Outdoor Patients Department of a tertiary care hospital in Karachi were recruited for the study. Descriptive statistics were used for data elaboration. SPSS v 21.0 was used for data analysis.

Results: Out of 163 patients, the cohort was almost equal in term of gender distribution. Sixty-one percent had urban residency of Karachi city and $62(38.04 \%)$ were categorized as elderly patients. Overall, poor health literacy status was reported among the study respondents. Health literacy was evident with patient's knowledge about medications: knowledge of adverse effects; language barriers and perception about role of exercise in improving quality of life.

Conclusion: Poor health literacy was associated with multiple factors that adversely affect patient's pharmacotherapy plans. Urgent measures by using a collaborative approach of physicians, pharmacist and nurses are required to improve health literacy of Pakistani population.
\end{abstract}

Keywords: Health literacy; Assessment; Cardiovascular; Pakistan

\section{Introduction}

Health literacy is a constellation of skills that range from the ability to read, seek, understand, evaluate and utilize health-related information. Based on the said information, individuals make informed choices to reduce health-related risks and to improve quality of life [1]. Health literacy is a pivotal tool at patient's disposal to perform and manage administrative (scheduling appointment, filling and understanding of consent forms) and clinical tasks (explaining medical history, understanding and following instructions for a therapy, procedure and care) [2]. However, not all patients have the same health literacy skills and level of understanding needed to rationally comprehend healthrelated information [2].

The existing literature provide empirical evidence that patients with limited health literacy tend to lack health related knowledge and are reported with poor health status [3]. Likewise, low health literacy has been frequently accompanied with poor therapy outcomes and improper use of healthcare services [4]. Medication non-adherence is a cause of growing concern for the clinicians, healthcare systems, and public health policy makers owing to strong evidences about its prevalence and association with the adverse outcomes and much higher costs of care [5]. It has been proposed that the limited literacy levels may be linked to poor compliance with pharmacotherapy [6]. Yet, the relationship between health literacy and medication adherence is still obscure (Powers and Bosworth, 2006). Seemingly, inadequate health literacy has been shown to affect patient's ability to identify medicines [7] and to interpret medicine warning labels [8]. Plethora of literature evidences suggest a strong connection between inadequate health literacy and worse health outcomes, such as little knowledge about health and medication non-adherence, etc [9]. Nevertheless, poor health outcomes due to inadequate health literacy have been attributed to one's ability to make sense of health information [10] along with inability to self care and to access healthcare services
[11]. More interestingly, health literacy has been a stronger correlate of health status than the education status and socio-demographic variables [12-14].

Shifting our concerns to the issue of health literacy in Pakistan, there is scarcity of evidence regarding the role of health literacy on treatment outcomes, medication adherence or use of health care services. However, it is highly unlikely that all intricate, complex and multifaceted associations of health literacy affecting patient outcomes can be studied at once. Thus, we aimed to study commonly reported health literacy factors affecting patient access to health care services, the ability of self-care and general understanding of health care provider during the encounter [15].

\section{Materials and Method}

\section{Study design, participants and sampling}

The study was designed as a cross sectional descriptive survey. Patients with cardiovascular complication and visiting Cardiology Outdoor Patients Department (OPD) of a tertiary care institute in the city of Karachi, Pakistan were targeted for the study. A time-based sampling criteria was used where by all patients with cardiovascular problems visiting the OPD were included for the period of three

*Corresponding author: Fahad Saleem, School of Pharmaceutical Sciences, Universiti Sains Malaysia, Malaysia, Tel: 0060124003956; E-mail: fahaduob@gmail.com

Received September 12, 2015; Accepted October 30, 2015; Published November 07,2015

Citation: Saleem F, Hashmi FK, Atif N, Bukhari NI, Ahsan M, et al. (2015) A Cross Sectional Assessment of Health Literacy among Cardiovascular Patients in Karachi, Pakistan. Health Econ Outcome Res Open Access 1: 101. doi $10.4172 / 2471-268 \times / 1000101$

Copyright: $\odot 2015$ Saleem F, et al. This is an open-access article distributed under the terms of the Creative Commons Attribution License, which permits unrestricted use, distribution, and reproduction in any medium, provided the original author and source are credited. 
months. One hundred and sixty three respondents fulfilled the inclusion criteria and were included in the final analysis.

\section{Inclusion and exclusion criteria}

For the enrolment of subjects, the patient inclusion criteria were cardiovascular diseases. Patients with co-morbidities were also included. Adults having complete medical record at the institute and consenting to participate in the study were included. Patients not willing to consent, having mental disabilities/impairments and having incomplete medical record wereexcluded.books or case files.

\section{Study instrument}

Data was collected by using a pre-validated questionnaire. The questionnaire included common parameters related to health literacy by observing community health literacy related clinical trends and practices. The questionnaire was piloted among 25 patients and was tested for reliability and validity. Little modification was needed before the research team approved the final version. Data from pilot study was not included in the final analysis.

\section{Data analysis}

The data was analyzed using the SPSS $\mathrm{v} 21.0$. The individual parameters were assessed for their percentage contribution in determining health literacy and the prevalence of each parameter among the samples under study.

\section{Ethical considerations}

To date, there is no ethical requirement for non-clinical observational studies in Pakistan [16]. However, permission to conduct the study was taken from the medical superintendent of the respective institute. In addition, written consent was also taken from the patients prior to data collection. The patients were informed about the research initiatives, confidentiality of their responses and their right to withdraw from the study with no penalty or effects on their treatment.

\section{Results}

\section{Frequency of demographic variables}

Table 1 present the distribution of demographic variables. Out of 163 patients, $52 \%$ patients were males and approximately $98.8 \%$ of the respondents were married. Sixty one percent belonged to the urban residency (Table 1).

\section{Health literacy among the study respondents}

Patients were asked about level of understanding of physicians' instructions and the interpretation of the message. Fifty-seven percent of the patients reported inadequate understanding of the physician instructions. In addition, confidence and trust of patients on medicines was analyzed and majority of the patients (56\%) lacked trust in safety and efficacy of medicines. Additionally, $57 \%$ of the patients reported lack of the necessary understanding about their disease. Almost one third of patients lacked knowledge towards adverse drug effects and half of them showed no concern regarding the poly-pharmacy. Almost half of the respondents lacked proper understanding of medication use. Moreover, when the physician was asked to rate the compliance levels of patient, interestingly only $28.8 \%$ of the patients were found to be non-compliant as shown in (Table 2).

Communication issues were identified as major barriers affecting the communiqué between patients and health care professionals. Sixty percent of the participants faced linguistic problems during conversation and information sharing sessions with the physician. Another indicator of health literacy that was included in the questionnaire was the identification of medications. The results suggested that only $2 \%$ of the patients could not identify their medicines, $9 \%$ identified their medicines on colour and 50\% patients identified their medicines by pack shape and colour of medicines. Thirty nine percent of the patients identified their medicines on basis of written information on the package (Table 2).

\section{Discussion}

There is considerable agreement among healthcare professionals that health literacy levels define overall success in treatment outcomes in terms of therapy compliance, disease reckoning and prudent display to complete health related administrative and clinical tasks [17]. Inadequate health literacy contribute results in unfortunate treatment outcomes owing to patient's inability to assess and use health care system, to attend health appointments, to understand health related documents, and to follow prescription directions and drug therapy plan [18].

The current study suggested inadequate health literacy affecting patient's understanding of physician's directions, drug therapy, and drug related adverse reactions. Moreover, the results also presented linguistic barriers in addition to the health literacy that result in further aggravation of murky situation. Within this context, National Health Survey of Pakistan (NHSP) during 1990-94 suggested that cardiovascular morbidities are more dominant in the urban population of Pakistan $[7,19]$. Therefore, much care is needed for patients with cardiovascular diseases on a daily basis by individual patients. Selfcare requires proper assimilation and application of disease and drug knowledge along with related skills. Presumably, adequate health literacy is critical in ensuring apposite patient compliance and proficiency in self management. Data from this study reinforced the importance of health literacy in adequate patient compliance, self care and reckoning of disease severity for a timely visit to their medical practitioner. Additionally, despite marginal literacy levels, health

\begin{tabular}{|l|c|c|}
\hline Demographic characteristics & N & $\%$ \\
\hline Gender & & 51.53 \\
\hline Male & 84 & 48.47 \\
\hline Female & & \\
\hline Age (years) & 0 & 0 \\
\hline $28-27$ & 7 & 4.29 \\
\hline $28-37$ & 14 & 8.59 \\
\hline $38-47$ & 52 & 31.90 \\
\hline $48-57$ & 62 & 38.04 \\
\hline $58-67$ & 28 & 17.18 \\
\hline >67 & & 1.23 \\
\hline Marital Status & 2 & 98.77 \\
\hline Single & 161 & \\
\hline Married & 100 & 61.35 \\
\hline Residential status & 63 & 38.65 \\
\hline Urban & & 20.86 \\
\hline Rural & 34 & 34.97 \\
\hline Educational status & 57 & 21.47 \\
\hline Illiterate & 35 & 12.27 \\
\hline Primary & 20 & \\
\hline Secondary & 17 & \\
\hline Higher Secondary & & \\
\hline Graduate & & \\
\hline
\end{tabular}

Table 1: Demographic characteristics of the study respondents. 
Citation: Saleem F, Hashmi FK, Atif N, Bukhari NI, Ahsan M, et al. (2015) A Cross Sectional Assessment of Health Literacy among Cardiovascular Patients in Karachi, Pakistan. Health Econ Outcome Res Open Access 1: 101. doi: 10.4172/2471-268x/1000101

Page 3 of 4

\begin{tabular}{|c|c|c|c|}
\hline Factors examined & Responses & Number & Frequency \\
\hline \multirow[t]{4}{*}{ Physician's Conversation Understanding } & Not understood & 12 & 7.36 \\
\hline & Little Understanding & 92 & 57.06 \\
\hline & Average Understanding & 56 & 34.97 \\
\hline & Full understanding & 1 & 0.61 \\
\hline \multirow[t]{4}{*}{ General knowledge about disease } & Lack of Information & 24 & 15.34 \\
\hline & Less knowledge & 92 & 57.06 \\
\hline & Average Knowledge & 44 & 27.61 \\
\hline & Sufficient Knowledge & 0 & 0.00 \\
\hline \multirow[t]{2}{*}{ Language barriers } & Face Problems & 65 & 39.88 \\
\hline & Do not face Problems & 97 & 60.12 \\
\hline \multirow[t]{4}{*}{ Knowledge about medicines in use and dosage } & Lack of Knowledge & 68 & 41.72 \\
\hline & Less Knowledge & 58 & 35.58 \\
\hline & Average knowledge & 33 & 20.25 \\
\hline & Well versed & 4 & 2.45 \\
\hline \multirow[t]{4}{*}{ Knowledge of Adverse effects } & Lack of Knowledge & 102 & 62.58 \\
\hline & Less Knowledge & 54 & 33.13 \\
\hline & Average knowledge & 7 & 4.29 \\
\hline & Well versed & 0 & 0.00 \\
\hline \multirow[t]{2}{*}{ Ever faced problem medicines } & Face Problems & 94 & 57.67 \\
\hline & Do not face Problems & 69 & 42.33 \\
\hline \multirow[t]{4}{*}{ Trust in efficacy and safety of medicines } & No response & 30 & 18.40 \\
\hline & Lack of trust & 91 & 55.83 \\
\hline & Slightly dubious attitude & 27 & 16.56 \\
\hline & Confidence on efficacy \& safety & 15 & 9.20 \\
\hline \multirow[t]{4}{*}{ Patient's comprehension of poly pharmacy } & No response & 17 & 10.43 \\
\hline & Not concerned & 82 & 50.31 \\
\hline & Mixed response & 36 & 22.09 \\
\hline & Concerned attitude & 28 & 17.18 \\
\hline \multirow[t]{4}{*}{ Basis of identification of pills } & No understanding & 3 & 1.84 \\
\hline & By pill colour & 15 & 9.20 \\
\hline & By pack shape and colour & 82 & 50.31 \\
\hline & By written information on Package & 63 & 38.65 \\
\hline \multirow[t]{3}{*}{ Patient compliance as rated by Physician } & Non-compliant & 94 & 57.67 \\
\hline & Average compliance & 38 & 23.31 \\
\hline & Highly compliant & 31 & 19.02 \\
\hline \multirow[t]{3}{*}{ Frequency of Cardiology OPD visits } & Fortnightly & 27 & 16.56 \\
\hline & Monthly & 86 & 52.76 \\
\hline & Others & 50 & 30.65 \\
\hline \multirow{3}{*}{ Perception about role of exercise and diet in therapy } & Disagree & 5 & 3.07 \\
\hline & Not sure & 81 & 49.67 \\
\hline & Agree & 77 & 47.24 \\
\hline
\end{tabular}

Table 2: Factors affecting health literacy level.

seeking practices of people dwelling in various regions of Pakistan require serious attention to increase the level of awareness and public literacy, especially among the women belonging to rural areas of all four provinces of Pakistan, to divest them of prevalent myths and superstitions affecting health seeking and self care behaviours [20].

It is beyond doubt that patient's ability to read, listen and comprehend health information is vital in managing and improving health. As evident from the data that four crucial and interlinked indicators (patient's understanding of physician, knowledge of the disease and drug, trust in medicines and compliance) affecting health outcomes were found to be poor and beyond patient's comprehension to assimilate health information and to proceed with self care. Similarly, a number of studies have shown that patients with inadequate health literacy are unable to formulate a beneficial relationship between life style modifications (physical activity, smoking cessation and dietary modifications) and cardiovascular disease prevention [21].
Our data is complete harmony with published reports exhibiting a strong correlation between health literacy and importance of life style modifications.

Unexpectedly, $63 \%$ of the patients lacked knowledge of adverse drug reactions while only $17 \%$ of the patients were concerned about polypharmacy. Interestingly, literature evidences suggest poor associations between health literacy and poly-pharmacy, health literacy and adverse drug reactions [22]. However, our data focused on the probable link between health literacy and knowledge of adverse drug reactions rather than incidences of adverse drug reactions. Furthermore, language barriers to communicate with health care providers coupled with inadequate health literacy further worsened patient's vulnerability to comprehend instructions from health care providers - while literature reports are conflicting regarding the impact of language barrier and outcomes of hospital care [23]. Importantly, according to studies guidance provided by pharmacists and allied health care professionals 
Citation: Saleem F, Hashmi FK, Atif N, Bukhari NI, Ahsan M, et al. (2015) A Cross Sectional Assessment of Health Literacy among Cardiovascular Patients in Karachi, Pakistan. Health Econ Outcome Res Open Access 1: 101. doi: 10.4172/2471-268x/1000101

may be effective in preventing and controlling the CVD burden. In this regard, studies suggest that cardiac patients, both inpatient as well as outpatient department, may benefit from integrated approaches to reduce the linguistic and cultural barriers $[24,25]$. In conclusion, our data suggested that inadequate health literacy coupled with language barriers could further aggravate the enormity of the problems, faced by the patients, ranging from inability to comprehend physician conversation, poor understanding of disease and medicine, lack of proper knowledge regarding adverse drug reactions, repercussions of poly-pharmacy, poor compliance to drug therapy and lack of trust in medicines. However, it is pertinent to mention that adapting a collaborative care approach with empowering clinical and hospital pharmacists to provide much demanding role as sole provider of pharmaceutical care and counselling (disease and medicine) could help overcome issues associated with inadequate health literacy.

\section{Conclusion}

Poor health literacy shapes as barrier to access healthcare services and to appropriate health treatment among cardiovascular patients. Poor health literacy was associated with multiple factors that adversely affect patient's pharmacotherapy plans. Urgent measures by using a collaborative approach of physicians, pharmacist and nurses are required to improve health literacy of Pakistani population.

\section{References}

1. Zarcadoolas C, Pleasant A, Greer DS (2005) Understanding health literacy: an expanded model. Health Promotion International 20: 195-203.

2. Kindig DA, Panzer AM, Nielsen-Bohlman L (2004) Health literacy: a prescription to end confusion. National Academies Press, Washington, USA

3. DeWalt DA, Berkman ND, Sheridan S, Lohr KN, Pignone MP (2004) Literacy and health outcomes. Journal of General Internal Medicine 19: 1228-39.

4. Berkman ND, Sheridan SL, Donahue KE, Halpern DJ, Crotty K (2011) Low health literacy and health outcomes: an updated systematic review. Annals of Internal Medicine 155: 97-107.

5. Ho PM, Bryson CL, Rumsfeld JS (2009) Medication adherence its importance in cardiovascular outcomes. Circulation 119: 3028-3035.

6. Williams MV, Davis T, Parker RM, Weiss BD (2002) The role of health literacy in patient-physician communication. Family Medicine 34: 383-9.

7. Kripalani S, Henderson LE, Chiu EY, Robertson R, Kolm P, et al. (2006) Predictors of medication self-management skill in a low-literacy population. Journal of General Internal Medicine 21: 852-6.

8. Davis TC, Wolf MS, Bass PF, Middlebrooks M, Kennen E, et al. (2006) Low literacy impairs comprehension of prescription drug warning labels. Journal of General Internal Medicine 21: 847-851.
9. Kalichman SC, Rompa D (2000) Functional health literacy is associated with health status and health-related knowledge in people living with HIV-AIDS. Journal of Acquired Immune Deficiency Syndromes 25: 337-344.

10. Pignone MP, DeWalt DA (2006) Literacy and health outcomes: is adherence the missing link. Journal of General Internal Medicine 21: 896-7.

11. Easton P, Entwistle VA, Williams B (2010) Health in the'hidden population'of people with low literacy. A systematic review of the literature 10: 459.

12. Gazmararian JA, Baker DW, Williams MV, Parker RM, Scott TL, et al. (1999) Health literacy among Medicare enrollees in a managed care organization. Journal of American medical Association 281: 545-551.

13. Davis TC, Crouch MA, Wills G, Miller S, Abdehou D (1990) The gap between patient reading comprehension and the readability of patient education materials. The Journal of Family Practice 31: 533-8.

14. Baker DW, Parker RM, Williams MV, Clark WS, Nurss J (1997) The relationship of patient reading ability to self-reported health and use of health services. American Journal of Public Health 87: 1027-1030.

15. Nutbeam D 1999 Literacies across the lifespan: Health literacy. Literacy and Numeracy studies 9: 47-55.

16. National Bioethics Committee Pakistan (2004) Ethical Research CommitteeGuidelines.

17. de Castro SH, Brito GN, Gomes MB (2014) Health literacy skills in type 2 diabetes mellitus outpatients from an university-affiliated hospital in Rio de Janeiro, Brazil. Diabetology \& Metabolic Syndrome 6: 126.

18. Holt G, Dorcheus L, Hall E, Beck D, Ellis E, et al. (1992) Patient interpretation of label instructions. American Pharmacy 32: 58-62.

19. Jafar TH (2006) Women in Pakistan have a greater burden of clinical cardiovascular risk factors than men. International Journal of Cardiology 106 348-354.

20. Anwar M, Green J, Norris P (2012) Health-seeking behaviour in Pakistan: A narrative review of the existing literature. Public Health 126: 507-17.

21. Safeer RS, Cooke CE, Keenan J (2006) The impact of health literacy on cardiovascular disease. Vascular Health and Risk Management 2: 457-64.

22. Mosher HJ, Lund BC, Kripalani S, Kaboli PJ (2012) Association of health literacy with medication knowledge, adherence, and adverse drug events among elderly veterans. Journal of Health Communication 17: 241-251.

23. Karliner LS, Kim SE, Meltzer DO, Auerbach AD (2010) Influence of language barriers on outcomes of hospital care for general medicine inpatients. Journal of Hospital Medicine 5: 276-282.

24. Galdas PM, Ratner PA, Oliffe JL (2012) A narrative review of South Asian patients' experiences of cardiac rehabilitation. Journal of Clinical Nursing 21 $149-59$.

25. Fletcher GF, Berra K, Fletcher BJ, Gilstrap L, Wood MJ (2012) The integrated team approach to the care of the patient with cardiovascular disease. Current Problems in Cardiology 37: 369-397. 